\title{
Application of analytic hierarchy process to evaluate design criteria for humane trap cage
}

\author{
Sivajothi Paramasivam¹, Hari Krishnan Munisamy², and Santhansamy Rayappan ${ }^{1}$ \\ ${ }^{1}$ School of Engineering, UOW Malaysia KDU University College, Jalan Kontraktor U1/14, Seksyen U1, 40150 Shah Alam, Selangor, Malaysia \\ ${ }^{2}$ Ascend I-Corporation Sdn. Bhd, No 58, Jalan Masjid 3/69, Seksyen 3, 46000 Petaling Jaya, Selangor, Malaysia
}

ABSTRACT - Atrocities against stray animal's especially large number of scavenging street dogs have increased at an alarming rate nationwide. Relevant authorities, in view of controlling stray animal population and curb chronic infections mulled cracking down on stray dogs using inhumane methods such as usage of tranquilizers or forcefully capturing. Thus, causing injuries, trauma and potentially death to these captured strays. Even though statistics about the number of violent incidents against strays remains unknown but animal welfare groups report constant complaints regarding animal cruelty. Animal activists mooted a request to design and built a modernize efficient yet low cost trap cage with a provision of technology which are normally ignored by many quarters; as a vehicle to educate the public on humane and compassionate ways to treat stray animals. The design of the cage involves consists of 3 parts, which was electronics hardware, communication system and critically the structure hardware whereby to withstand the possible aggressiveness of the animal. The objective of this paper is to present and apply the techniques of the analytic hierarchy process (AHP) in the prioritization and selection of design criteria of the trap cage. The finding shows that out of 5 design criteria, quality criteria is the most important criteria in designing of a humane trap cage issue. This is followed by innovativeness, cost, safety and aesthetics factors.
ARTICLE HISTORY

Revised: $24^{\text {th }}$ September 2020

Accepted: $30^{\text {th }}$ September 2020

\section{KEYWORDS}

analytic hierarchy process multi-criteria decision making humane trap cage

design criteria

stray animals

\section{INTRODUCTION}

A complex yet challenging activity that is an integral part of a product development phase is the selection of the right design concepts. The reason being the selection activity which predominantly reviewed at the conceptual design stage critically involves decision making that aptly fulfils the changing needs and preference of the clients. In fact, the determination to produce the best engineering design concept involves innovative and creative efforts primarily as a result of brainstorming sessions or insights into customers' changing needs. A string of factors drives this design phase in order for a successful implementation of product design taking into account the most important aspect expected from the intended output. However, it is imperative that customer intended needs and preferences are closely reviewed and addressed in a systematic approach without incurring huge overheads which potentially leads to extra redesign costs and potentially delay in product realization $[1,2,3]$. It was acknowledged that majority of real-world decision problems traditionally involve multiple performance attributes, including both quantitative attributes and qualitative attributes of subjective nature. Therefore, a decision support model utilizing multi-criteria decision making (MCDM) technique will significantly aid decision makers in developing sound and defensible policies. The aim of this paper and its associated study is to determine and develop a decision support model that utilizes multi-criteria decision making technique to design a trap cage that has an element of humane approach in trapping stray animal. In this relation, this unique product design is basically a trapping mechanism with provision of technology that function in a way that it would not injure or harm the stray animals when it is in use. This designed cage is envisaged to be promoted by the NGO to the local municipal city councils nation-wide. This specific need was mooted to address the increase of strays where they would cause physical disturbance to the public community. Thus, this study develops a decision modelling procedure, based on the Analytical Hierarchy Process (AHP).

\section{OVERVIEW OF THE DESIRED CONCEPTUAL DESIGN APPLICATION}

Atrocities against stray animal's especially large number of scavenging street dogs have increased recently. Some agencies in view of controlling stray animal population mulled cracking down on stray dogs using inhumane and primitive methods; thus causing injuries, trauma and potentially death to these strays. Even though statistics about the number of violent incidents against strays remains unknown but in light of growing sensitivity to the rights of animals; animal welfare groups report constant complaints regarding animal cruelty. It was indicated that even though the cage method is 'primitive' which is normally used to capture stray animal with food in them in order to lure them into the cage, element of injury or trauma is normally overlooked and shown no importance. However, despite deploying a rather primitive 
approach, the luring process itself is already very difficult as stray animals are usually more cautious and does not fall to lures easily and it might take several days just to get the animals to be interested to the cage. In certain cases, the cage will also not be able to capture the animals as the animals might escape by digging out the cage from the ground or simply destroy the cage itself. In addition, the capturers have to stay nearby during the strays' active period, mostly hours in the night just to recollect the cage if the capture is successful. Hence, the effort towards to design and built the trap cage with some provision of technology is much anticipated. Figure 1 shows the flowchart of the trap cage concept base on insight of the client.

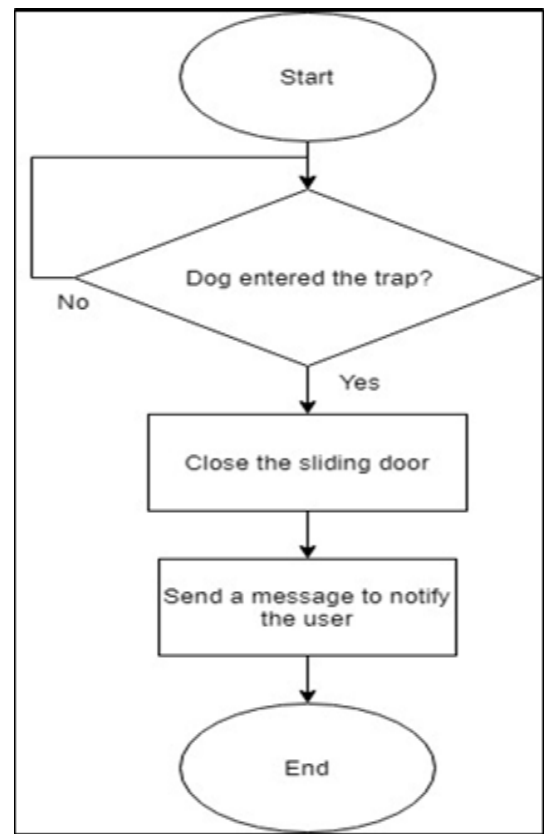

Figure 1. Flow chart of Trapping Cage Concept.

This decision method is rather complex as the uniqueness in meeting were quite challenging based on the client's inputs and aspiration, for one reason the trapping process should not cause injuries, trauma and potentially death to these captured strays and subsequently transfer them back to pets' home for further care such as neuter, protect and feed. As an initial start, the cage is expected to be built with sturdy material with a degree of mobility for the animal rescuer to easily relocate the dogs to the animal shelter after being captured. Furthermore, it was indicated that the system has a display console unit that is activated with element of innovation in order to automate the locking system with electronic hardware system coupled with certain degree of intelligence without any sharp edges at the entrance of the cage and subsequently a triggering mechanism of notification to a remote positioned user. In pursuit of improvement and based on statements of the clients, the conceptual design framework for the trap cage was created as reflected in Figure 2.

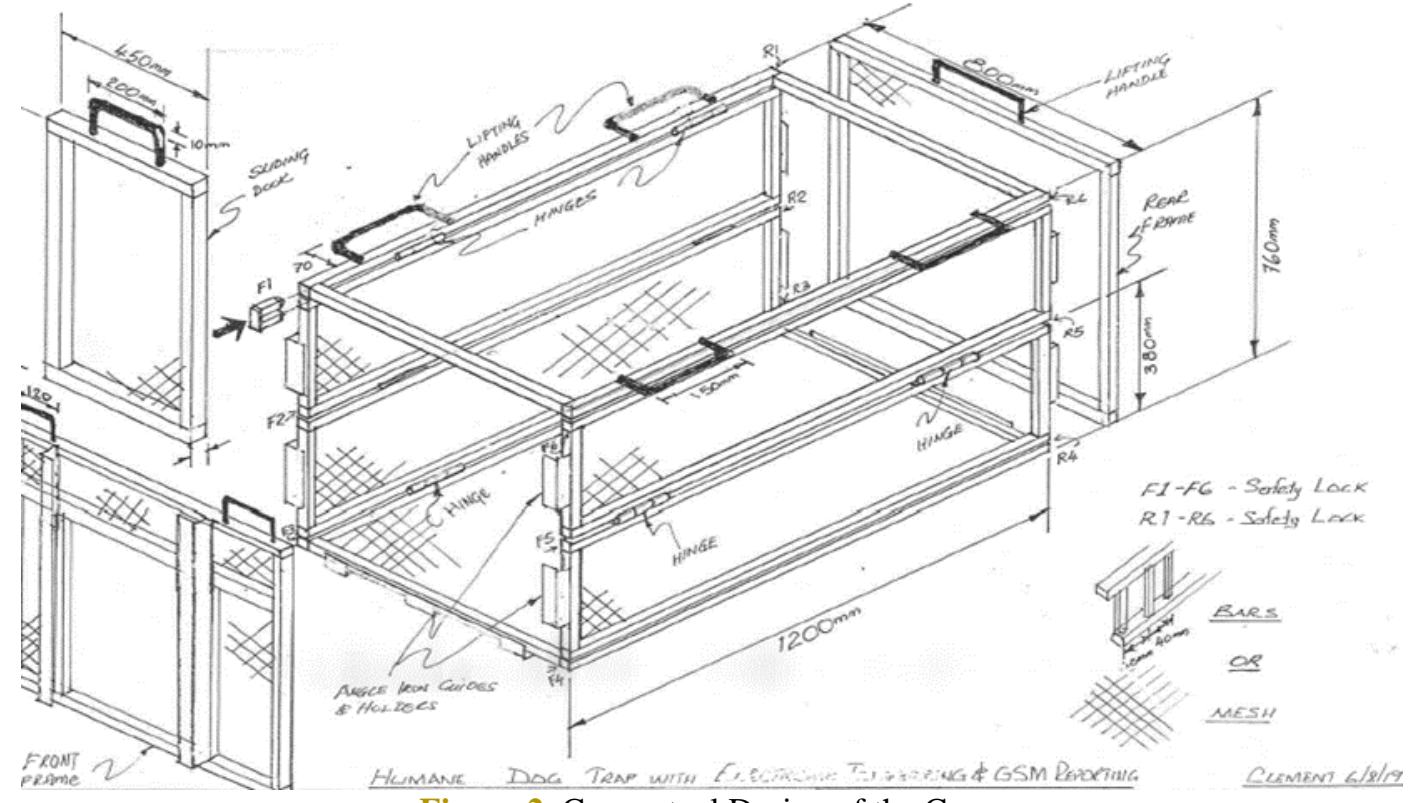

Figure 2. Conceptual Design of the Cage. 
This conceptual design was produced with a degree of innovation and technology whereby the humane dog trap consists of electronic devices with sensory system that pings on distance measurement to automate the trapping procedure of the humane dog trap. Furthermore, the operational part of the unit, it was suggested to incorporate a display unit in the console to indicate level of readiness of the trap to the user. The conceptual design infuses element of technology as part of alerting mechanism of successful capture. However, investigation was further needed to find out the preferences of the design criteria of the cage as the intention was to capture the stray animals.

\section{AN ANALYTICAL HIERARCHY PROCESS (AHP) - RANKING THE PREFERENCE OF THE DESIGN CRITERIA OF CAGE}

The primary objective in this activity to understand expert opinion of these specific members to aid in setting the priorities and consequently to conceive the best option that would be effective for successfully shaping the product. According to [3,4], it was crucial that engagement with client was important as it provides a basis to weight the available options for making decisions by taking into account the various criteria to strategically draw a conclusion. In tackling a project of this nature, MCDM method was suggested to be the desired technique. In this context, Saaty's analytic hierarchy process (AHP) forms as the dominant method of MCDM that provides a suitable framework for this related problem [2,5]. As acknowledged by many authors, AHP gain popularity due to its simplicity, transparent process and accuracy with regards to expressing one's opinion based on only two alternatives [6,7,9]. In supporting this view, [10] added that the analytical hierarchy process approach yield positive results as it was administered and verified in an investigative study on the university-industry partnership initiatives on ranking preference of linkages by industry of various sectors with the following approaches, namely identification of industrial respondent, development of hierarchical structure, data tabulation, assignment of weight and eventually producing output. Furthermore, this technique has gained popularity in many scopes ranging from banking, transportation, telecommunication, software evaluation and other evaluations. According to [11], AHP has three elements namely analytic, hierarchy and process in view of solving complex problems. The AHP method dominantly involves the given problems to be examined in a tree-like hierarchy approach and subsequently establishes hierarchies with mutual influences. In this pursuit, the areas of concern for the design of trap cage were determined to be safety (SA), aesthetics (AE), quality (QU), cost (CO) and innovativeness (IN) impacts.

Various sub-criteria were defined for the main criteria and these were listed below:

- Safety: Reliable (RE) and robust (RO)

- Aesthetics: Collapsible ease of storage (CES) and compact ease to transfer (CET)

- Quality: Product with substantial value-added (PVA)

- Cost: Cost of maintenance (CM)

- Innovativeness: Ultrasonic locking system (ULS), remote alerting/signalling (RAS) and provision for tracking system (PTS).

Following the determination of these criteria, hierarchical model was set up and is shown in Figure 3.

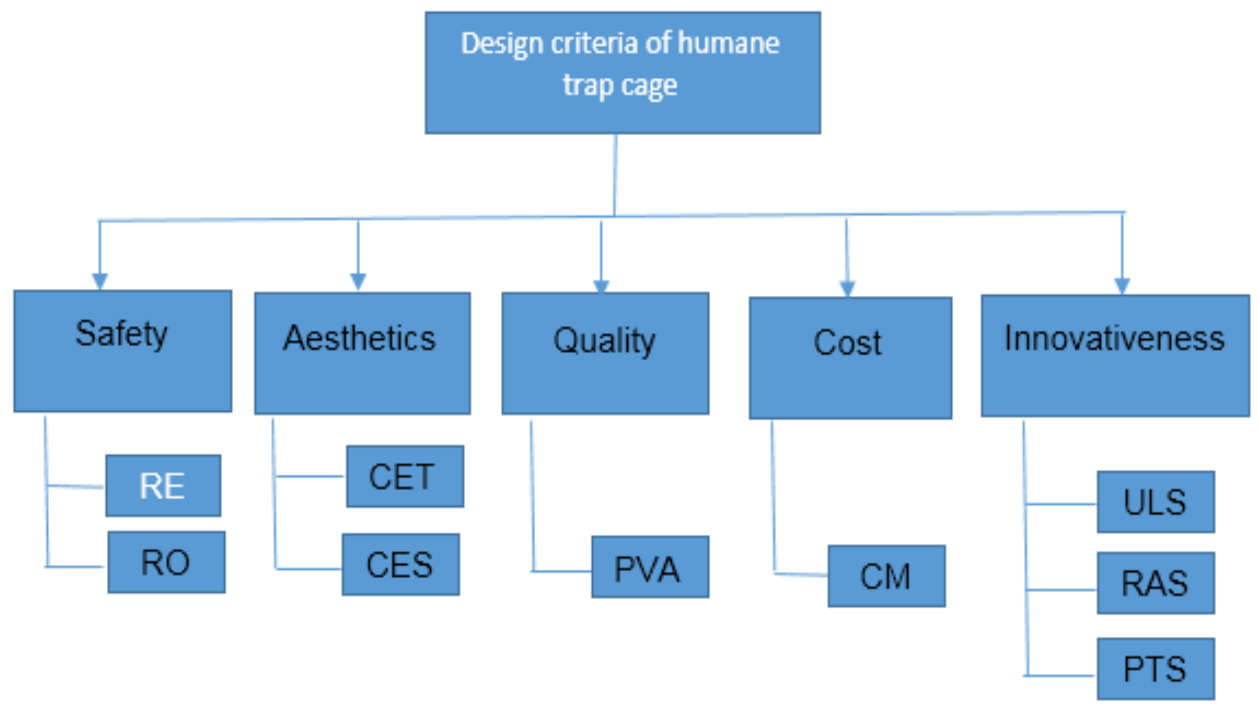

Figure 3. Hierarchical model for Design criteria selection of Trap Cage.

The adoption of AHP approach which would reflect, namely identification of industrial respondent, development of hierarchical structure, data tabulation, assignment of weigh and eventually producing output. AHP technique as shown in 
Figure 4 has a locus on survey study which has direct bearing on the process to choose between alternatives based on multiple criteria and eventually to make decision by using a pairwise comparison approach specifically those involve multi criteria system of many levels. Generally, the pairwise approach involves a process of comparing entities in pairs, and eventually selection of the preferred pair or has a greater amount of some quantitative properties. In this relation, the process of data input for pairwise comparison is simple yet straightforward. Furthermore, decision makers normally respond to pairwise comparison question based on their insights and experience relative to the multi-criteria decision problem.

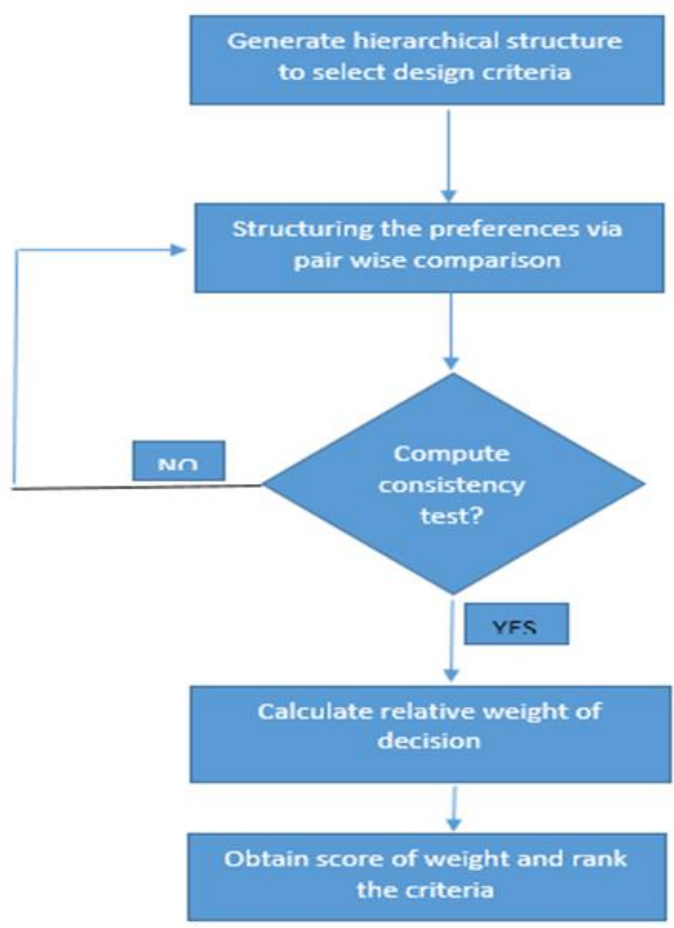

Figure 4. Flowchart of the AHP approach.

The level of preference or intensity by the decision maker falls in the range of 1 to 9 as shown in Table 1 and also called "Saaty's fundamental scale" [2].

Table 1. Saaty's Fundamental Scale of Judgment and its Description [2].

\begin{tabular}{cll}
\hline $\begin{array}{l}\text { Intensity of Importance, } \\
\text { ai;aj }\end{array}$ & \multicolumn{1}{c}{ Definition } & \multicolumn{1}{c}{ Explanation } \\
\hline 1 & Equal importance & Two attributes impact equally to the objective \\
\hline 3 & Moderate importance & $\begin{array}{l}\text { Judgment and insight slightly favouring one attribute } \\
\text { over another }\end{array}$ \\
\hline 5 & $\begin{array}{l}\text { Strong importance } \\
\text { attribute over another }\end{array}$ \\
\hline 7 & $\begin{array}{l}\text { Very strong or } \\
\text { demonstrated } \\
\text { importance }\end{array}$ & $\begin{array}{l}\text { An attribute that reflects dominance in practice and } \\
\text { impact very strongly over another }\end{array}$ \\
\hline 9 & $\begin{array}{l}\text { Extreme importance } \\
\text { The evidence impacting one attribute over another is } \\
\text { of the highest possible order of affirmation }\end{array}$ \\
\hline $2,4,6,8$ & $\begin{array}{l}\text { Intermediate values } \\
\text { between two adjacent } \\
\text { judgments }\end{array}$ & \\
\hline
\end{tabular}

According to [2,9], the number of comparisons is determine by the number of elements in the scope of study and is defined by the given Equation 1.

$\mathrm{n} *(\mathrm{n}-1) / 2$ (whereby $\mathrm{n}$ is the number of elements).

For example, if there are 5 elements/attributes to be compared, thus, 10 comparisons are produced $(5 *(5-1) / 2=10)$. The analysis involves data to be tabulated into an Excel spreadsheet. Once done, this entails numerical value to be average 
among the respondent's survey. This was performed by carrying out a comparison matrix A, of dimensions $\mathrm{n} X \mathrm{n}$, where $\mathrm{n}$ is the number of alternatives in that level. Consequently, the next stage involves placing every element aij as the result of a pairwise comparison denoting the dominance of element i relative to element $\mathrm{j}$. As such, to calculate the new weight using all of the pairwise comparison, a reciprocal matrix was introduced in this stage. As introduced by Saaty, comparison matrix A is calculated. Let $C 1, C 2, \ldots C n$ indicate the set of elements and the quantified judgment on a pair of elements $C i, C j \ldots$ to be aij; and n-by-n matrix A as Equation 2.

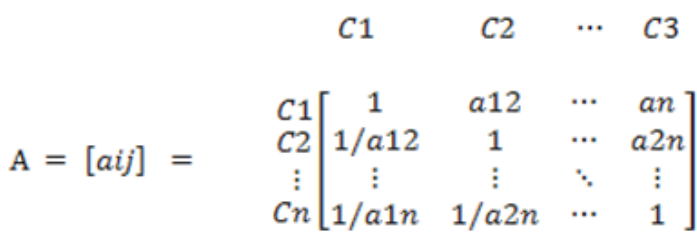

This entails normalization of the new composite weights, the magnitude, and the priority vector points out the relative preference of the decision element. As a result, the pairwise comparison approach used in the AHP procedure requires a strict rational approach. The next stage calculation entails determining the consistency index (CI) for each respondent. This is to measure the degree of coherence of the responses in the pairwise comparisons. Authors have indicated that as a rule of thumb, when using AHP technique, low-consistency respondents should be excluded from the analysis or, at least, assigned a low weight $[2,8,9]$.

\section{RESULT}

The computational analysis was carried out using the pairwise comparison approach and the outcome of summation process reflects in Table 2.

Table 2. Pairwise comparison matrix of the main criteria.

\begin{tabular}{cccccc}
\hline Client 3 & SA & AE & QU & CO & IN \\
\hline SA & 1 & 7 & 1 & 0.200 & 0.143 \\
\hline AE & 0.143 & 1 & 0.143 & 0.143 & 0.143 \\
\hline QU & 1 & 7 & 1 & 7 & 7 \\
\hline CO & 5 & 7 & 0.143 & 1 & 0.143 \\
\hline IN & 7 & 7 & 0.143 & 7 & 1 \\
\hline Total & 14.143 & 29 & 2.429 & 15.343 & 8.429 \\
\hline
\end{tabular}

The result of these matrices includes evaluation of the sub-criteria which is reflected below in Table 3 .

Table 3. Relative weights of main and sub-criteria.

\begin{tabular}{clc}
\hline \multicolumn{1}{c}{ Criteria } & Relative Weight \\
\hline Safety & & 1.869 \\
- & Reliable (RE) & 0.571 \\
- & Robust (RO) & 4.000 \\
\hline Aesthetics & Collapsible ease of storage (CES) & 0.314 \\
$-\quad$ & 3.982 \\
$-\quad$ Compact ease to transfer (CET) & 0.571 \\
\hline Quality & & 4.600 \\
- & Product with substantial value-added (PVA) & 1.000 \\
\hline Cost & & 2.657 \\
- & Cost of maintenance (CM) & 1.000 \\
\hline Innovativeness & 4.429 \\
- & Ultrasonic locking system (ULS) & 2.667 \\
- & Remote alerting/signalling (RAS) & 3.000 \\
- & Provision for tracking system (PTS) & 0.437 \\
\hline
\end{tabular}

\section{CONCLUSION}

This paper adopts the AHP approach for determining priorities on design criteria of the trap cage that attempts to modernize the product as desired by animal activist. According to the Table 3, quality criteria is the most important criteria in designing of a humane trap cage issue. This is followed by innovativeness, cost, safety and aesthetics factors. In addition to this, the most important sub-criteria is the robustness of the trap cage vis-vis ability of product performance is not affected by the uncertain input of environmental conditions. 


\section{ACKNOWLEDGEMENT}

The authors would like to thank Malaysian Animal Welfare Associations (MAWA) for initiating this idea and the Capstone Project students of January-May 2019 semester of the undergraduate engineering programme under the supervision of Dr Praveena in producing a prototype for the clients, which was partially funded by School of Engineering, UOW Malaysia KDU.

\section{REFERENCES}

[1] Sauli, H., Matti, H., \& Mikko, S. (2007). Comparison of four existing concept selection methods. Guidelines for a Decision Support Method Adapted to NPD Processes, Paris, 1- 11.

[2] Onder, E., \& Dag, S. (2013). Combining analytical hierarchy process and TOPSIS approaches for supplier selection in a cable company. Journal of Business, Economics \& Finance, 2(2), 56-74.

[3] Luqman, M., Rosli, M. U., Khor, C. Y., Zambree, S., \& Jahidi, H. (2018). Manufacturing process selection of composite bicycle's crank arm using analytical hierarchy process (AHP). In IOP Conference Series: Materials Science and Engineering, 318(1), 1-8. DOI: 10.1088/1757-899X/318/1/012058

[4] Ishizaka, A., \& Labib, A. (2011). Review of the main developments in the analytic hierarchy process. Expert systems with applications, 38(11), 14336-14345. DOI: 10.1016/j.eswa.2011.04.143.

[5] Danesh, D., Ryan, M. J., \& Abbasi, A. (2015). Using analytic hierarchy process as a decision-making tool in project portfolio management. WASET International Journal of Economics and Management Engineering, 9(12), 4194-4204. DOI: $10.5281 /$ zenodo. 1110373

[6] Brent, A. C., Rogers, D. E., Ramabitsa-Siimane, T. S., \& Rohwer, M. B. (2007). Application of the analytical hierarchy process to establish health care waste management systems that minimise infection risks in developing countries. European Journal of Operational Research, 181(1), 403-424. DOI:10.1016/j.ejor.2006.06.015.

[7] Ho, W., Higson, H. E., \& Dey, P. K. (2007). An integrated multiple criteria decision making approach for resource allocation in higher education, International Journal of Innovation and Learning, 4(5), 1-27. DOI:10.1504/ijil.2007.012958.

[8] Alam, M. N., Jebran, J. K., \& Hossain, M. A. (2012). Analytical Hierarchy Process (AHP) Approach on consumers preferences for selecting telecom operators in Bangladesh. In Information and Knowledge Management, 2(4), 7-18.

[9] Prusak, A., Stefanów, P., Niewczas, M., \& Sikora, T. (2013, June). Application of the AHP in evaluation and selection of suppliers. In 57th EOQ congress quality renaissance co-creating a viable future, 17-20.

[10] Sivajothi, P., John, K. T. \& Kanesan, M., (2015), Investigating University-Industry partnership of Higher Engineering Education using Cause-Effect analysis and Multi-criteria Decision making: A Malaysian Perspective. International Journal of Applied Engineering Research, 10(20), 41444-41450.

[11] Saaty, T. L. (1990). How to make a decision: the analytic hierarchy process. European Journal of Operational Research, 48(1), 9-26. DOI: 10.1016/0377-2217(90)90057-i 